\title{
Lethargic Research Projects: Student-supervisor's Dilemmas in Managing Research Projects
}

\author{
Kanyesigye Rullonga Monicah \\ Ernest Cook Ultrasound Research and Education Institute (ECUREI), Kampala, Uganda
}

Email address:

mrullonga@gmail.com

\section{To cite this article:}

Kanyesigye Rullonga Monicah. Lethargic Research Projects: Student-supervisor's Dilemmas in Managing Research Projects. Higher Education Research. Vol. 5, No. 2, 2020, pp. 37-43. doi: 10.11648/j.her.20200502.11

Received: December 17, 2019; Accepted: January 4, 2020; Published: March 10, 2020

\begin{abstract}
Starting an academic research project is an exciting journey which students approach with high zeal, excitement and passion. Eventually, the excitement reduces; very few complete on time, a sizable number abandon their studies and others drag on for long beyond the allowable academic time. In fact, most of the students end up applying for extension of time before they are deregistered. On estimate, only $10 \%$ of those who begin their $\mathrm{PhD}$ journey are able to complete in an average 4 years' time. This paper analyzed the dilemmas students go through in their research process and the challenges supervisors meet in handling doctoral research projects. The study employed an exploratory design. Self-administered questionnaires were used on 42 respondents who included; $\mathrm{PhD}$ students on a research project, $\mathrm{PhD}$ student supervisors and $\mathrm{PhD}$ holders who had undertaken a research project. Data analysis was done concurrently with data gathering using content analysis method. The study findings indicated that supervisor challenges are mainly institutional constructed, while students recounted lack of clear guidance and orientation on the research process, attributed to both the institution and supervisor. Mutually, there is a tendency to assume that both parties have a clear familiarity with the study process. The study recommends the need for attention in; planning, design and orientation of both students and supervisors in managing academic research projects specifically, outlining expected milestones at each level. The study designed a triad supervisory model that can be adopted by institutions of higher learning in Africa to improve graduate rates, solve the student-supervisor challenges and improve $\mathrm{PhD}$ quality of research.
\end{abstract}

Keywords: PhD Studies, Academic Research, Supervision Dilemmas

\section{Introduction}

Undertaking an academic project is an uphill struggle for many scholars who invest their money and time at the expense of family and career. Most of those who brave the journey lose morale along the way and, either abandon the project, or drag on slowly to completion. The few in the latter category are eventually deregistered for taking so long in the system beyond the course period and end up joining the former category. The importance of developing social relevant research is undeniable, particularly because doctoral studies and research must be original, creative and innovative. Delmont et al 2000 as cited by Murray 2002 opined that the success or failure of a $\mathrm{PhD}$ cannot be reduced to a set of written rules [1]. The doctorate should be able to prepare the scholar to improve the research training component for a specialization in one's career and be able to make an original contribution to knowledge; however, a broader discussion must be stimulated regarding the concept of "useful knowledge", its understanding and consequences. In many institutions of learning, scholars are expected to carry out research, write an in-depth and coherent thesis, undertake teaching and publish papers within the average three to four years for a doctoral study. This however, is rarely achieved [2]. This paper analyses why the process takes longer than is timed and how this lengthy process can be managed mindful of the quality produced.

Most institutions of higher learning internationally, require that in order for one to apply for promotion to professorship, they should have supervised a doctoral student to completion among other. However, with the sluggish process of getting students to complete their research projects, this is a high point to reach for those who would otherwise wish to be elevated to that level. While there are a number of $\mathrm{PhD}$ routes, the traditional model is being challenged with; $\mathrm{PhD}$ by publication, professional doctorates and the New Route PhD 
[3]. The international context demonstrates the existence of an increasing number and a greater diversity of students enrolling in doctoral programmes.

This paper analyzes the dilemmas students go through in their research process and the challenges supervisors meet in managing research projects. The paper presents empirical data from students that have either completed a research project and those still grappling to complete. The paper further presents the opinions of supervisors in view of what they go through to support doctoral students. The paper is intended to provide guidance for research scholars and their supervisors on the likely delays and challenges in the research journey and finally suggests harmonious grounds on which both parties can work together to produce quality research projects without unnecessary delays.

The study had the following objectives:

i. To seek views of supervisors and students on challenges they face in supervising/undertaking research projects respectively.

ii. To propose ways of how students and supervisors can work together to write quality research projects and complete in the shortest time possible.

Supervision of students at $\mathrm{PhD}$ level involves the process of identifying a researchable topic for study, identifying a problem, coming up with a road map in form of methodology of the study that will be undertaken. Many institutions of higher learning provide research guidelines for students to follow in order to produce their research work. In essence, supervision involves learning and teaching during the research process. The process of supervision requires one to be knowledgeable in guiding the student, while the learner needs to be willing to accept guidance, counsel and modeling by the supervisor.

Many institutions of higher learning have enrolled students for a 3 year $\mathrm{PhD}$ program; however, low rates of completion are registered at the end of the 3 years. The international context demonstrates the existence of an increasing number and a greater diversity of students enrolling in doctoral programmes. For instance, at Uganda Management Institute, out of the 20 students who registered for a PhD study in 2012, only $2(10 \%)$ were able to complete after 6 years in 2018 . Out of 19 students who registered for the same program in 2013 , only $3(16 \%)$ had completed the course after 6 years in 2019 . This means that $90 \%$ and $85 \%$ respectively for both intakes have completed the $1 \frac{1}{2}$ years of coursework but are still grappling with the research project. Increasing accountability puts a great pressure on Higher Education institutions, particularly about completion rates and time to complete the doctoral studies [4]. In countries like Malaysia for instance, the production of $\mathrm{PhD}$ holders has not been substantial and this attrition rate has been attributed to supervision as a core reason [5], further opine that this attrition this low and low completion rate is a grave concern because it is seen as a waste of both human and financial resources.

Supervision can be looked at in form of developmental, integrated, and orientation specific models. Under developmental models, there are three levels of supervision: the beginning- where there is self-learning and a lot of dependency on the supervisor. The second level of intermediate is where one is motivated to do their part but only depends on the supervisor for an understanding of difficult issues. In the last level which is the advanced, there is autonomy; the supervisees function independently, seek consultation when appropriate, and feel responsible for their correct and incorrect decisions.

In a review of developmental supervision models, patterns were noted. Studies revealed that as supervisors gained experience, their behavior changed and so was the supervisory relationship. There appeared to be a scientific basis for developmental trends and patterns in supervision [6]. Women were perceived as more effective supervisors than the men [7]. Considering the different levels in the development model, one is bound to assume that the learning process may take un-identified period of time, to shift from one level to another, and hence a lethargic process adopted if the supervisee does not learn soon enough, to graduate to the next level.

Under integrated models of supervision, one combines an attention to three supervisory roles with three areas of focus. Supervisors might take on a role of "teacher" when they directly lecture, instruct, and inform the supervisee, or, might take on the counseling role noticing their blind spots or the manner in which they are unconsciously "hooked" by a client's issue. When supervisors relate as colleagues in the course of their duty, they might act in a "consultant" role. The purpose of adopting a "counselor" role in supervision is the identification of unresolved issues clouding a relationship. Determining which role the supervisor takes either as a teacher, counselor or consultants might be a prerogative of the supervisor. Helshe also put into consideration their interpersonal skills in relating with supervisee. While the later might be an easy role to take especially at doctoral level, the counseling role requires the skills, competencies and high level of interpersonal skills on the part of the supervisor. In all these, the supervisee's willingness to be handled in either form is not considered.

In Orientation-specific models of supervision, the supervisor believes that the best part of their work is the analysis of practice for true adherence to the "brand" of intervention. Both the supervision and supervisee look in each other for signs of expertise and weakness. This leads to each person attributing a degree of influence or authority to the other. The mid-stage is characterized by conflict, defensiveness, avoiding, or attacking. Resolution leads to a "working" stage for supervision. The last stage is characterized by a more silent supervisor encouraging supervisees in their tendency toward independence [6]. In a way, orientation specific models have a high dependency on the evaluation and appraisal of the supervisor and their opinion of how the process should flow.

Although the above models help us to understand the process of supervision, the questions is how long should this process take in either model to move from the first stage to the next stage, up to completion of research projects. While this study appreciates the different models in understanding the 
supervision process, the interrogation is on understanding the challenges both the learners and supervisors go through under whatever model they choose to take.

Murray (2011) advances that supervisors should possess recognized subject expertise and should have received training for supervision with continuous development [1]. He further argues that institutions of higher learning should provide codes and guides, the support for research, assessment criteria, selection of external examiners and remunerating the supervisors. In return, Gurnam et al [5] posit that supervisors should provide their intellectual expertise to boost the supervisees' self-confidence and self-esteem.

Looking at the above models, we need to consider two things; one, the challenges faced by both parties, and two; the quality produced in the different models. Murray proposes a set of expectations of a supervisor; that he/she should give feedback on one's writing, set writing goals from the start of the thesis and all the way through to the end and motivate the student to start writing and keep writing throughout the project He further posits that the supervisor is the most important person in the academic life of a research student and therefore the student should find out his/her research interest, recent publications, experience of supervising research students and if they are supervising for the first time, find out if there is a backup provision [1]. Hung \& Smith (2008) as cited by Gurnam et al, [5] advance that the attitude and behavior of a supervisor towards the supervisee, determines the eventual behavior of the supervisee. They may end up as calm persons, who see things sharply, effective learners, or as not creative at all. It is further posited that the student should be interested in knowing how much time the supervisors will have for him/her and the role the supervisor expects to take and if it fits in the student's pattern of work. All these details as advanced by Murray [1] help the students to set an explicit journey for their project, by demystifying a number of challenges that might come their way in future.

There are common problems research students meet along the way. These include; poor planning and management of the project, methodological difficulties in the research, writing, isolation and inadequate or negligence of supervision among others [8]. These challenges if known early by students should be able to help them develop ideas of how to circumvent their appearance in the process. This may help research students to sail through their research process with time. Murray [1] proposes that students should write goals at the onset which should define the purpose of their writing task, define their audience, the scale and scope of their writing, number of words to write and how long it will take to write. A number of authors have given guidelines on how to write a thesis, providing a good starting point for researchers in addressing their audiences, produce quality work, understanding the relationship with supervisors and ensuring logical writing with locus and focus [9-16].

\section{Methods}

Primary information was collected from students and supervisors answering questions on challenges of lethargic research problems drawing from their experiences from different academic institutions globally.

The study employed a cross sectional survey using questionnaires to collect data both qualitative and quantitative data. Participants were; PhD students $(N=12)$ who had undertaken a $\mathrm{PhD}$ project for more than 3 years and were still on going, $\mathrm{PhD}$ holders $(N=17)$ who had completed a $\mathrm{PhD}$ course of more than 3years, and $\mathrm{PhD}$ supervisors $(N=13)$ who had supervised or are supervising $\mathrm{PhD}$ students on a research project. These were purposively selected; drawing them from various institutions of learning regardless of where they studied from or were rendering their supervisory services but as long as they fitted within the inclusion criteria above. Participants completed questionnaires based on their experiences and opinions on research projects. Data analysis was done concurrently with data gathering using content analysis method [17].

A total of 60 questionnaires were sent out by email to the three categories as outlined above targeting 20 respondents for each category. In response, only 42 questionnaires were returned. In the category of $\mathrm{PhD}$ on going students, the response rate was $60 \%$, (12 out of 20 ) compared to $85 \%$ (17 out of 20) for the $\mathrm{PhD}$ holders. For those in the supervisory category 13 out of 20 questionnaires were returned (65\%). In total, the response rate was $70 \%$ which was considered acceptable compared to the recommended $52.7 \%$ by Baruch \& Holtom [19].

\section{Results}

Graph one below shows the number of respondents for the study categorized by academic level as $\mathrm{PhD}$ students, $\mathrm{PhD}$ holders (with no supervisory roles) and $\mathrm{PhD}$ holders as $\mathrm{PhD}$ student supervisors.

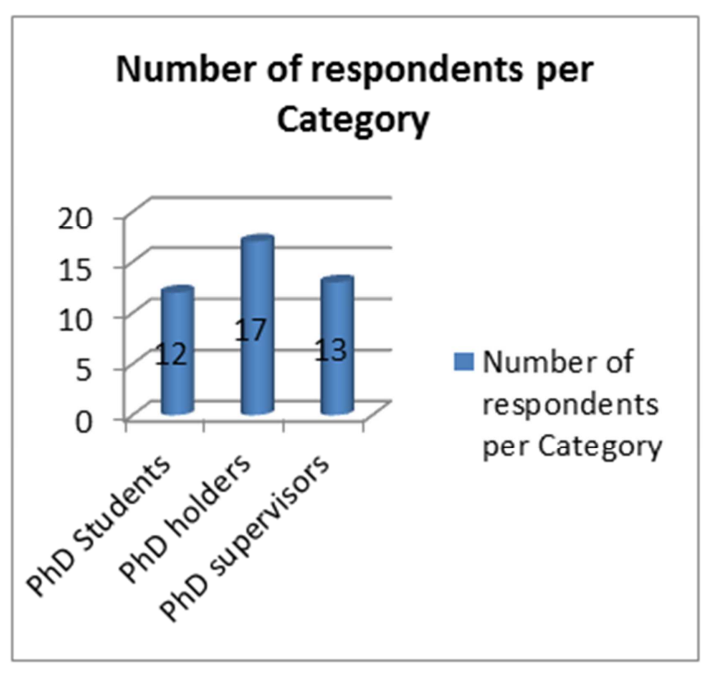

Source: Study data.

Figure 1. Showing the number of respondents by category.

Study participants were asked about the most challenging part in the research process for those with supervisory roles. 
The study revealed that there is poor conceptualization of ideas by students to the supervisor's expectations. While some supervisors felt that students were not seeking support in areas where they needed help, a number of supervisors noted that remuneration was not worth the effort and time invested to supervise. It was noted that research work is very demanding with low benefits in terms of remuneration.

Asked about how long the research project has taken them to completion, $1 \mathrm{PhD}$ holders had taken less than one year to complete their research project; six had taken between 2 to 3 years while 11 indicated a length between 3 to 5 years compared to 9 of the respondents who had supervisory roles.

Respondents were asked to indicate in no particular order, what they consider as the most challenging part of the research project. The following were the responses as presented in figure 2 below:

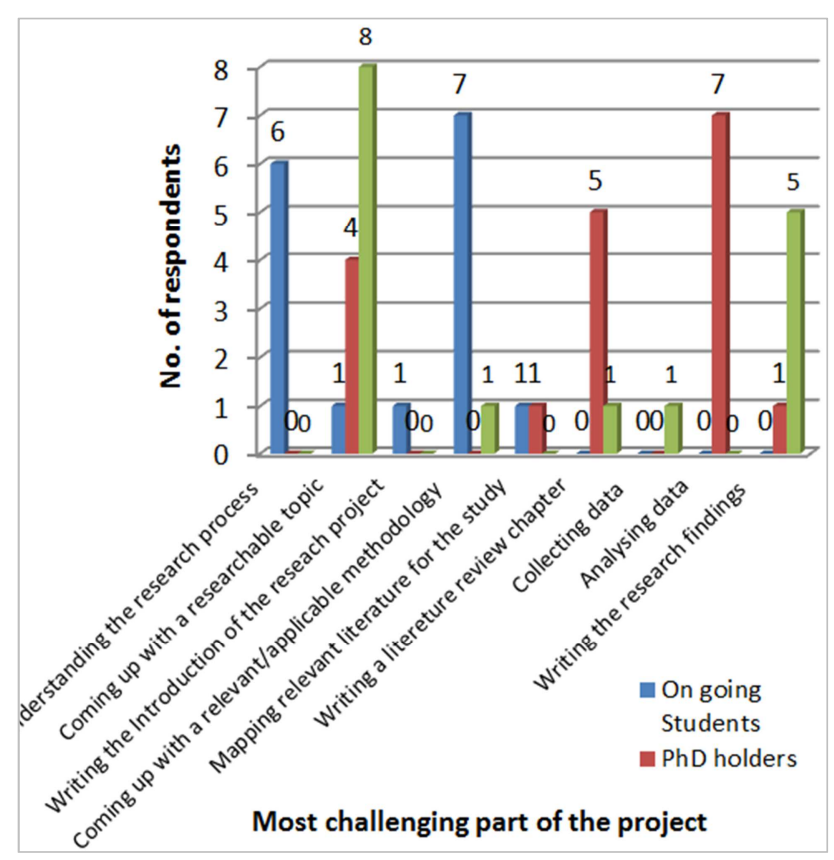

Source: Study data.

Figure 2. Showing the most challenging part of the research project.

From the study, it was found out that coming up with a researchable topic was the most challenging part of project and mainly from supervisors. Supervisees take long to come up with a topic that the supervisor feels is worthwhile, although students felt that writing the introduction chapter was the hardest part. Indeed this can be challenging for students to have their grounding on the research project, however, $\mathrm{PhD}$ holders felt that data analysis was the most complicated part in the research process.

All respondents indicated that research work was very critical and gave a sense of achievement after completion; however, one respondent, a $\mathrm{PhD}$ holder indicated that research was only a formality and not critical; that they could as well have done without it.

Scholars were asked how they felt about their supervisors in terms of knowledge, communication and team work, the following responses were recorded.

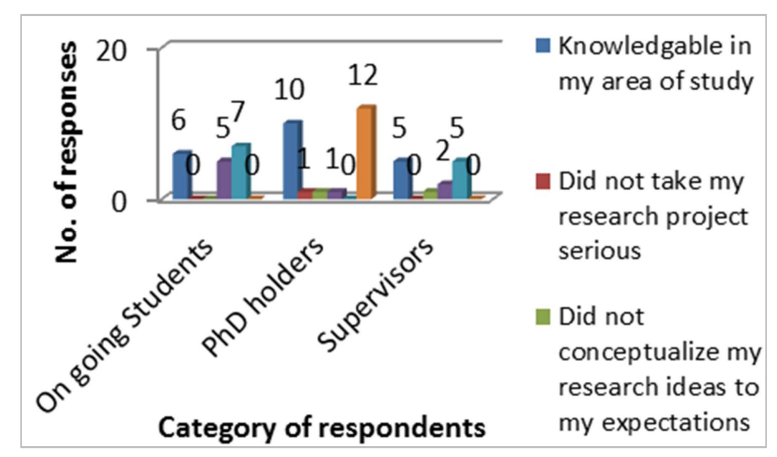

Source: Study data.

Figure 3. Showing respondents' perceptions of their supersors knowldge, communication and teamwork skills.

Ongoing students as well as supervisors felt that either party was not responding to comments addressed on time. This is likely to drain the process with one party blaming the other for untimely response. However, there was a general appreciation of the supervisor as a subject expert and very knowledgeable in the area of study. The $\mathrm{PhD}$ holders felt they had received limited support from their supervisors.

In order to help doctoral scholars produce quality research work and complete research projects on time, critical areas were underscored which should be addressed. In their order of importance, the following were areas of concern on how scholars felt that research quality can be improved and produced in time.

i. Provide a forum for students to have regular symposiums to share their research progress with peers.

ii. Reduce on bureaucracy of research approvals for students.

iii. Give students and supervisors orientation on the research process, methodology and how to draw a workable research road map.

iv. Remunerate supervisors to put effort in supporting students.

v. Have a working research team at the institution's level to support students in their research work from proposal level through data analysis.

vi. Involve students in the choice of who supervises them.

vii. The most outstanding concerns were on proving a forum for regular symposium where students can meet with peers and present their progress. It was further found out that bureaucracies for approval of research at institutional level are high and need to be reduced. In the order of preference was the need to have working research teams at institutional level to support students in their research work process. This would help them to produce quality work and on time.

viii.Qualitative data collected mainly targeted the respondent's recommendations for the challenges encountered in the research project. A number of ideas were suggested for consideration as helpful in the research project. These responses were categorized by source from the three types of respondents.

A. Ongoing $\mathrm{PhD}$ students 
Respondents in this category indicated a need to have continuous mentoring by both the institution and supervisor besides increasing accessibility on the part of the supervisor. They further suggested the need to receive orientation support from institutions of higher learning for every stage of their research journey specifically in data analysis and presentation.

B. PhD Holders' category

Respondents expressed a need to review and consider more time to be allocated to research than class work noting that there was a tendency for students to concentrate on class work and end up fatigued when the time for research project writing comes. They further opined that institutions of higher learning should get a commitment from supervisors before assigning them students such that issues of delay and lack of time to support students is minimized. In most cases, supervisors accept the responsibility to supervise students but drop them along the way without regard for the student's time and career progress especially when the supervisee and supervisor disagree on line of thought. Further, the respondents revealed that some of the supervisors are not responsive and therefore proposed that team supervision should be encouraged such that in case one supervisor drops out, the supervisee has a fallback position.

\section{Supervisors' category}

Those in supervisory roles specified that there is need to for students to dedicate more time for research and writing; taking research as a very important part of their degree and career. They further posited that all $\mathrm{PhD}$ students should receive training in critical writing skills in order to be able to write quality research projects. Supervisors further suggested the need by institutions to assess students' competency and ability to undertake research before being admitted into a $\mathrm{PhD}$ research project.

Cross cutting responses focused on the institutions of learning as the starting point in guiding and solving the challenges met in the research process. They recommended the need for formal and constant interaction between the supervisor and students in form of symposium and other ways of peer review and expert advice.

\section{Discussion}

While students felt they need for more attention from the supervisors in terms of timely response to addressed comments and work in progress, it was noted across the board that the need for peer review and engagement in form of symposiums can play a vital role in helping scholars keep on track, produce quality work and reduce on laxity of those that may be on a lone journey of $\mathrm{PhD}$. Murray [1] proposes study buddies who should be individuals one can have regular discussions with in navigating new developmental stages. He posits that learners should meet to write and write when they meet to avoid getting into the habit of talking about writing and not doing it. In such meetings, one should be able to share what they have written since the last meeting, discuss with the buddy and set a sub goal of their next writing [1]. This in addition helps to avoid writer's block and to master the art of writing. Boice 1994 proposes the strategies for "unblocking" such as free writing, writing with a supervisor, mind-mapping, verbal rehearsal and many others [19]. Peer meetings therefore, help scholars to keep on track and work smoothly with supervisors to address the lethargic challenges.

Bureaucratic procedures in research approvals involve presentations to Institutional Review Boards, Research Councils etc. - to ensure quality, acceptable research and approve protocols for research. The study indicated that these processes are lengthy and time -consuming which result in delaying students. Bureaucracy involved can be reduced keeping up with quality assurance, at the same time but increasing on turnaround time. It is always imperative to be mindful of the timelines that students have for academic achievement.

In preparing students for research, it is important to take them through the foundational courses of research without regard that they have studied research at the previous levels. Supervisors noted that students should be evaluated in terms of competency and capability to handle research projects. The understanding of $\mathrm{PhD}$ process and what it takes should be a clear step taken by institutions of higher learning. This helps to increase on completion rate, prepare students to understand the challenges in research data analysis that was scored by the $\mathrm{PhD}$ holders as the most complicated part of the research process. Foundational research process is an important part as a taught module for $\mathrm{PhD}$ students.

Support from institutions of higher learning in monitoring the progress of students is very critical in helping students gain momentum in continuing to write. The structures and processes that institutions of higher learning put in place help to track the students and keep them on course. Among others, the institutions should ensure that students and supervisors come up with a road map of how they are going to carry out the research with timelines that are followed and respected at each point of the journey. This is in agreement with the assertion of Phillips and Pugh [15] on research planning for quality output.

The role of the supervisor should be looked at beyond a facilitator, teacher, supporter and examiner but as an advisor and guide, who commits to walk the journey with the student from start to end without coercion but self-will and flexibility. While Brown and Atikins [8] look at a supervisor as a subject expert who is a critic of the students' writing, this role needs to be discussed at the onset of the research project for each party to understand their contribution into the project. In this way, the role of the supervisor could go beyond the traditional supervision and take a more pragmatic role of project ownership as a dual venture for both the student and supervisor. Lessing \& Schulze (2002), as cited by Gurnam et al [5] stress that a supervisor's role is to guide, advise, ensure scientific quality and provide emotional support to the supervisees among others.

\section{Recommendation}

As part of the codes and guides for institutions of higher 
learning in the research process, the mutual benefit of the research project should go beyond the award of the new qualification to positioning in research and teaching for the institution on the global arena. This study therefore recommends a Triad supervision model, which can be adopted to solve the lethargic challenges faced in doctoral research projects. While the student is adding to the body of knowledge, the supervisor is developing and guiding the student; the institution should also define their benefit in the process. This way, the project should be looked at as a threesome benefit for the parties; the institution outlining their benefit, as much as the supervisor and the student. A monitoring framework should be in place to highlight accomplishments and milestones along the way in order to complete the project in time with quality output. Ana (2011) recommends the necessity of developing training programs which can suitably respond to both doctoral supervisors and student's needs [20]. And this follows this study's recommended Triad supervision model below where such trainings may not necessarily be for students alone but supervisors as well with the involvement of the institutions as illustrated in the model below;

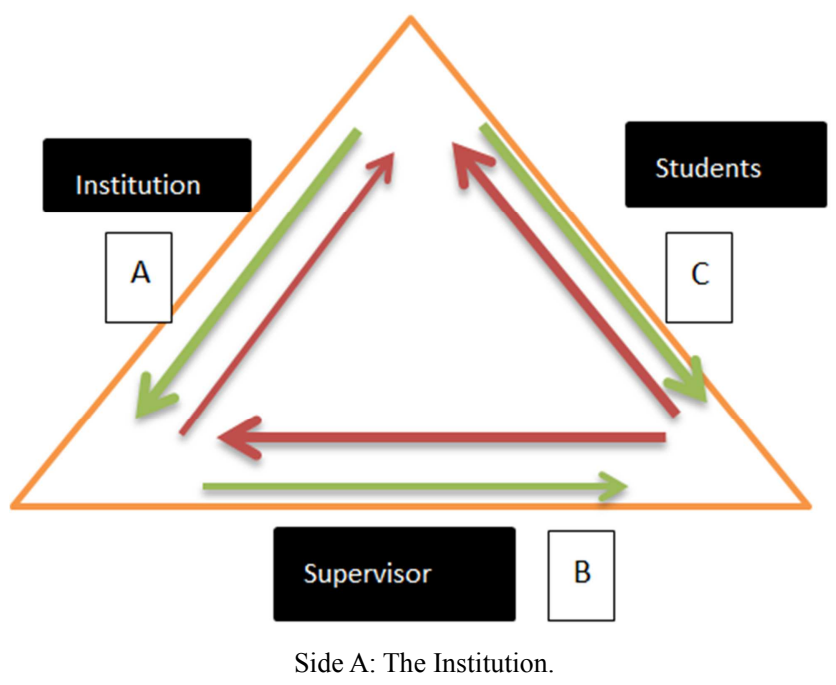

Figure 4. Proposed Triad Supervision Model for Doctoral research projects.

i. Comes up with guidelines and codes for research.

ii. Carries out training for both students and supervisors on the research process.

iii. Assigns appropriate research supervisors to students.

iv. Helps students with bureaucracies of approvals for research projects.

v. Organizes regular progressive symposiums with peers, students and supervisors.

vi. Monitors the road map designed for the research milestone and appropriately helps the students and supervisor to keep on truck.

vii. Carries out examination and over sees the publication of the research findings.

viii. Remunerates the supervisor for their time and effort appropriately.

Side B: The Student

i. Works with the supervisor to identify a researchable topic.

ii. Works with the supervisor on the roadmap and monitoring framework.

iii. Submits regular progress report to the institution on the roadmap.

iv. Evaluates the performance of the supervisor in terms of knowledge, guidance and responsiveness.

Side C: The Supervisor

i. Guides the student to shape the research project.

ii. Attends training programs from the Institution on the research project process.

iii. Walks the journey with the student through the research project as a guide, critic and mentor.

iv. Submits regular progressive reports to the Institution on the competencies, capabilities and performance of the student.

v. Examines the student's research writing.

\section{Conclusion}

With the Triad supervision model in place, the three parties have ownership of the product in terms of quality and are responsible for the project returns. In essence, if the three parties clearly undertake their roles, the challenges of sluggishness are likely to be minimized where there is mutual benefit for all the parties. It is equally essential that before one begins a doctoral research project, the processes are clearly thought out and solutions are outlined for the anticipated challenges in order to stimulate an engaged debate in writing.

\section{References}

[1] Murray, R. (2011). How to write a thesis (3rd ed.). Berkshire: Open University Press.

[2] Lee, A. (2008). How are Doctoral Students supervised?: Concepts of research supervision. Studies in Higher Education, 267-81.

[3] Park, C. (2005). New Variant PhD: the challenging nature of the doctorate in the UK. Journal of Higher Education Policy and Management, 189-207.

[4] Uganda Management Insitute. (2019, May 31). Uganda Management Insitute Report 2019. Graduation booklet. Kampala, Uganda: Uganda Management Insitute.

[5] Gurnam, K. S., Sarjit, K., Chan, Y. F., \& Farhana, W. Y. (2014). Postgraduate Supervision: Comparing student perspectives from Malaysia and the United Kingdom. Procedia - Social and Behavioral Sciences, 151-159.

[6] CYC-Online. (2001, January 24). CYC-Online. Retrieved August 28, 2019, from https://www.cyc-net.org/cyc-online/cycol-0101-supervision\% 20models.html

[7] Putney, M. W., Worthngton, E. L., \& McCullough, M. E. (1992). Effects of Supervisor and Supervisee Theoretical Orientation and Supervisor-Supervisee Matching on Intern's Percetions of Supervision. Jounal of Counselling Psychology, 258-265. 
[8] Brown, G., \& Atkins, M. (1994). Effective Teaching in Higher Education. London: Routledge.

[9] Bolker, J. (1998). Writing Your Dissertation in Fifteen Minutes a Day: A Guide to Starting Revising and Finishing Your Doctoral Thesis.. New York: Henry Holt.

[10] Glatthorn, A. (1998). Writing the Winning Dissertation: A step-by-step Guide. Thousands Oaks C. A: Corwin.

[11] Hampson, L. (1994). How's Your Dissertation Going? Students Share the Rough Reality of Dissertation Project work. Lancaster: Unit of Information in Higher Education.

[12] Moon, J. (1999). Learning Journals: A handbook for Academics, Students and Proffessional Development. London: Kogan Page.

[13] Murray, R. (1995). Writing and Dialogue for the PhD. Journal of Graduate Education, 103-9.

[14] Patridge, B., \& Starfield, S. (2007). Thesis and Dissertation Writing in a Second Language. London: Routledge.
[15] Phillips, E., \& Pugh, D. (2000). How to Get a PhD: A Handbook for Students and their Supervisors, 3rd edn. Buckingham: Open Univeristy Press.

[16] Swales, J., \& Freak, C. (1994). Academic Writting for Graduate Students: Esential Tasks and Skills. Ann Arbor: Univeristy of Michigan Press.

[17] Amin, A. (2005). Social Sciences Research, Conception, methodology and analysis. Kampala: Makerere University Printery.

[18] Baruch, Y., \& Holtom, B. (2008). Survey Response Rate Levels and Trends in Organisational Research. Human Relations, 1131-1160.

[19] Boice, R. (1994). How Writers Journey to Confort and Fluecy: A Pyschological Adventure. London: Praeger.

[20] Ana, V. (2011). Challenges to Doctoral Research and Supervision quality: A Theoretical Aprroach. Elsevier Ltd Science Direct, 3577-81. 